\title{
A Phase II Study to Evaluate Connections in Higher Risk for Heart Disease and Narcissists Appearance in Private Pharmacy Institutions Pune University India Behaviours among Men who Have Work with Men (Mm): Is there Evidence of an Effect?
}

\author{
Rahul Hajare* \\ Indian Council of Medical Research New Delhi, India \\ Received: 制 September 22, 2018; Published: 制 September 26, 2018 \\ *Corresponding author: Rahul Hajare, Indian Council of Medical Research New Delhi, India
}

\begin{abstract}
Respect can earn. Wrinkle shows life is loved your life and ageing with dignity. Self-admiration increasing day by day. According to a study conducted by the Private Pharmacy Institutions in Pune University, men women have a higher risk for Narcissists appearance compared with other reputed institutions in city across several modifiable risk factors. "Researcher highlights the impact of Narcissists orientation, specifically power politics identity, on the behavioural health of men women and suggests researcher and public health practitioners should develop tailored screening and prevention to reduce Narcissists appearance risk in hetero sexual men women in private pharmacy institutions in Pune University.
\end{abstract}

\section{Introduction}

Adult men are alcohol dependent accepted and narcissists appearance has not personality, that can keep under control, it can be honest that can pro narcissists. Narcissists will centric that lead to attraction, it has bisexuality can be identified by close monitoring with the exchange of face hormonal changes or design the forehead of narcissist personality [1,2]. Narcissist has diagnosed as disease:

a) It has genetically structure it can be controlled in early stage by meditation otherwise prepare for future, relating to, or characterized by sexual or romantic attraction to members of both sexes; also: engaging in sexual activity with partners of more than one gender.

b) Relating to, or involving both sexes $[3,4]$.

Bisexual reproduction. It cannot be ignore possessing characters of both sexes and especially both male and female reproductive structures: hermaphroditic one in hundred statistics. Narcissists always want to be the centre of attention. It will always expect their partner to acknowledge their gossip and appearance. Approximately six per cent of the population has Narcissistic Personality Disorder (NPD). NPD affects more men than women -
7.7 per cent men and 4.8 per cent women, according to research published in The Journal of Clinical Psychiatry. Know that another partner has NPD. Young healthy adults at private pharmacy pune university PPPU have identified warning signs that may be dating someone with NPD $[5,6]$. Here are some red flags to look out for, as reported in the Independent they make feel bad about nonnarcissistic. Do not expect a narcissistic boyfriend or girlfriend to be genuinely happy for others. Instead, they will most likely be overly critical or attempt to downplay accomplishments. They only like to talk about themselves all the time. If dating someone extremely self-absorbed, date night conversation will most likely revolve around his or her gossip and interests. Constant praise is what makes them happy. Narcissists always want to be the centre of attention and will always expect their partner to acknowledge their talents and appearance [7-9]. They are demeaning towards other people. Egocentrics often obsess over the negative aspects of other people's lives. Even their close friends and family members may not be spared from the judgment. Narcissists often think they can do a better job than others, which reinforces the belief that they are always right. They are sensitive and overreact. When a narcissist's emotional needs aren't met, their reaction is often grandiose. 
Many narcissistic people may appear extremely angry or cry until the other person apologises. They lack empathy $[10,11]$. Partner may offer to come over when they are having a bad day, but their motivation is most likely self-serving.

\section{Conclusion}

Narcissistic who have experienced intimate health disease are at greater risk for physical and mental health problems including posttraumatic stress disorder (PTSD), over sex and alcohol dependency. Most men women get a severe stroke and the impact of all may these costs. Researchers have reported that men women with these experiences are more difficult to treat; many do not access treatment and those who do, frequently do not stay because of difficulty maintaining helping relationships in regards imaginary respect and disrespect. However, these men women's perspective has not been previously studied in close monitoring narcissistic. The purpose of this study is to describe the experience of seeking help for alcohol dependency by Indian men women to avoid the present age short time. Men women with alcohol drugs dependency with a history of depression lead narcissistic want help however the health and social services do not always recognize or their symptoms of distress. Drug dependency and alcohol attempt thickens and stiffens artery walls, which can inhibit blood flow through arteries to organs and tissues that involved narrowed or blocked blood vessels that can lead to a heart attack.

\section{Recommendation}

a) Over narcissistic increases muscle tension and increase pain: The narcissistic acting as a natural pain which will further increase muscle soreness. Incorporating hydrotherapy as part of fitness holiday is a great way to recover after a day's training.

b) Injured Muscles: Being immersed in narcissistic raises the body temperature, reduces blood flow around the circulatory system and so alleviating pain. They obstruct circulation will in turn to injured micro tissues and damaged muscles or joints.

c) Weaken Immune System: The decreased blood flow and circulation of white blood cells around the body allows lymph (an immune system fluid that decline collect and get rid of wanted materials from the body) to be unmoved through the body more efficiently and therefore weaken the immune system, avoid fighting colds and illnesses.

d) Discourages Detoxification: This is the body's primary way of adding toxins and therefore the impurities and toxins are refused out through the skin to detoxify the body. e) Increases Stress: Narcissistic can help to increase blood pressure caused by stress. It may also fast the body's reaction to anxiety and decrease endorphins a natural stress fighter.

\section{Acknowledgment}

This study has been guided by under supervision and guidance of Renowned Laboratory Scientist Respected Dr. Ramesh Paranjape Red. Director and Scientist 'G' National AIDS Research Institute India. I express my sincere gratitude towards Respected Sir' for motivation and being great knowledge source for this research.

\section{References}

1. Rahul H (2018) Indian Women, Trauma and Hydroxyl Drugs Dependency: Connections and Disconnections in Heart Disease for Women. Int J Curr Innov Adv Res (2): 1-2.

2. Rahul Hajare (2018) Detection of High Addictive Habits Circulating Office in Charge of Private Pharmacy Institutions in Pune University India (Evidence Based Study of Late Report Office In Charge to College). Clinical Biotechnology and Microbiology 2(3): 377-381.

3. Rahul H (2018) Two Trajectories A Promise of Reform and Ashaaram Pattern. Degenerative Intellect Dev Disabilities 1(3): 1-3.

4. Rahul H (2017) Live and let live: Acceptance of learning disability of people living with co-educational pharmaceutical institute selffinanced and privately managed remote areas in India where stigma and discrimination persist. Current Opinions in Neurological Science 1(6): 311-313.

5. Rahul H (2018) Shocking Link of Rapid Rise in Pre-Cancer among the Healthy Adults in Pharmaceutical Institution Pune University India Living with Low Oxygen and Poor Sanitation Environment: Affordable Treatment Rate Three-Times Over. Glob J Add \& Rehab Med 5(5): 1-3.

6. Rahul H (2018) Regulation of Pharmacy Council of India and Assessment of Quality Life Among Single Mother-By-Choice 'Residing in slums Linkage Pharmaceutical Institutions in Pune, India. Drug Des Int Prop Int J 1(3): 1-2.

7. Rahul Hajare (2018) There is no Cure for the Cancer of Stupidity. Organic \& Medicinal Chem IJ 5(1): 1-3.

8. Rahul Hajare (2018) An Attempt to Eradicate Alcohol Dependency from Adult Men in Service Privately Managed Pharmaceutical Institutions in India. Toxicology and Applied Pharmacology Insights 1(1): 1-2.

9. Rahul H (2018) Assessment of the Depression-Level Effectiveness of the Curse Words in Young Adults in Private Co-Educational Pharmaceutical Institutions in Pune University Pharmaceutical Institutions Living with Poor Sanitation, India: A Pre-planned, Causal Pathway-Based Analysis. J Gastrointest Disord Liver Func 4(1): 6-10.

10. Rahul A Hajare (2018) 909090 Formulas and Symptoms of Adrenal Fatigue Syndrome (AFS) of Adult Men. Orthop \& Spo Med Op Acc J 1(3): $1-2$.

11. Rahul H (2018) No Fact Check, Pharmaceutical Institutions from Reputed Pune University and Socially Situated and Socially Constituted Agency. Orthop \& Spo Med Op Acc J 1(3). 
(c) This work is licensed under Creative

To Submit Your Article Click Here:

Submit Article

DOI: $10.32474 /$ SJO.2018.01.000111

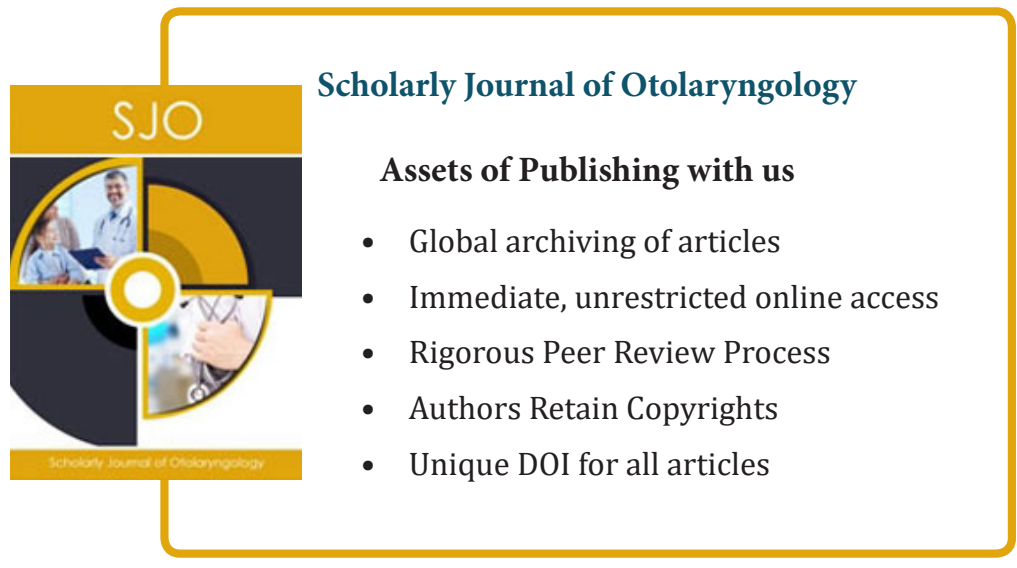

